\title{
Consumo: um convite para desbravar esse vasto campo de estudo
}

\author{
Bianca Leite Dramali \\ bianca.dramali@gmail.com
}

\begin{abstract}
Resumo
Através de leitura inicial de obras sobre o consumo, busco nesse artigo fazer uma breve revisão de obras seminais sobre o tema. São analisadas de maneira introdutória as obras de Mary Douglas, Colin Campbell, Daniel Miller e Everardo Rocha, teóricos renomados do consumo.
\end{abstract}

Palavras-chave: Consumo. Publicidade. Cultura. Mídia de Massa.

\section{Consumption: an invitation to break through this vast field of study}

\begin{abstract}
Through initial reading of works on consumption, I seek in this article a brief review of seminal works on the subject. Are analyzed in an introductory way the works of Mary Douglas, Colin Campbell, Daniel Miller and Everardo Rocha, renowned theoretical consumption.
\end{abstract}

Keywords: Consumption. Advertising. Culture. Mass Media.

"A fim de impressionar esses observadores efêmeros e a fim de manter a satisfação própria em face da observação deles, a marca da força pecuniária da pessoa deve ser gravada em caracteres que mesmo correndo se possa ler." (VEBLEN, 1980, p. 57).

\section{Introdução}

Através de leitura inicial de obras sobre o consumo, busco nesse artigo fazer uma breve revisão de obras seminais sobre o tema. São analisadas, de maneira introdutória, as obras de Mary Douglas, Colin Campbell, Daniel Miller e Everardo Rocha, teóricos renomados do consumo. Não tenho a pretensão aqui de fazer uma análise crítica das mesmas. Pretendo apenas deixar configurada uma revisão bibliográfica acerca do consumo.

Inicialmente, se faz necessário conceituar o que chamo de consumo neste artigo, Consumo é aqui entendido como fato social, processo de troca simbólica e sistema de comunicação. O consumo, entendido como sistema cultural, é uma das perspectivas possíveis de entender a nossa 
sociedade contemporânea - e talvez a mais adequada - já que é este fenômeno social que dá nome à mesma, como nos afirma Baudrillard em sua obra "Sociedade do Consumo".

Fato social total é, segundo Marcel Mauss, "um complexo específico de uma dada sociedade (ou de um tipo de sociedade), impossível de se sobrepor a qualquer outro" (MAUSS apud DUMONT, 1985, p. 12). Como um contágio emocional, o fato social parte do exterior para o interior de cada indivíduo e é por cada um desses retroalimentado, num processo dialético. Assim, afirma Dumont, "não existe fato sociológico independentemente da referência à sociedade global em questão.” (DUMONT, 1985, p; 13). Por isso, é importante que as análises empreendidas acerca do consumo sejam sempre relativizadas e contextualizadas em nossa sociedade de consumo, com seus valores, categorias, hierarquias e representações.

Podemos estudar o consumo a partir de suas práticas - aproximando-se da ideia de rito ou ritual -; das classificações identitárias que produz; e das representações midiáticas da cultura de massa, responsáveis pela narrativa desse fenômeno - aproximando-se da ideia de mito. Sempre refletindo sobre as dimensões culturais e simbólicas.

\section{Consumo: traços históricos}

Há uma vinculação entre mídia e consumo desde as suas origens, já que historicamente podemos identificar a simultaneidade do surgimento do anúncio, jornal e consumo, a partir de 1750. Consolidado no século XIX, o sistema de consumo está dado, com suas práticas e representações narrativas.

Com o advento do Iluminismo, o mundo deixa de apostar na permanência, contemplação valor do tempo passado - e passa ter força a transformação. Mobilidade social, por exemplo, passa a ser algo desejado e possível. E a marca do consumo auxilia na sinalização dessa transformação. Isso porque antes, sem a lógica cultural do consumo, a cultura material do indivíduo era dada pela posição determinada socialmente para ele; assim a lógica predominante era de um sistema de posições sociais. O fenômeno social do consumo, tal como conhecemos hoje, é uma invenção da sociedade moderno-contemporânea.

Recorrendo à teoria de Dumont acerca do individualismo, numa cultura material onde a posse e uso de objetos se dá porque a vida é assim, ou seja, onde a cultura material se dá pela posição social, o indivíduo é um fenômeno infra-social. Já numa sociedade onde a cultura material se dá através da lógica de ter ou não condição de consumir este ou aquele objeto, num sistema 
social aberto, desprendido do tecido social e de suas regras, o indivíduo pode ser entendido como um fenômeno sociológico. Aqui nasce a noção de indivíduo moderno e, com ela, a nossa sociedade de consumo.

Os estudos sobre a produção dominam a ciência até o século $\mathrm{XX}$, como se fosse a produção o motivo que nos leva a viver. Para os economistas - estudiosos da produção - com sua visão evolucionista, tudo tem que evoluir, por isso se faz necessário produzir mais e mais. Para eles, o consumo é mero reflexo da produção. Mas o que se dá na verdade é que é o consumo que motiva a produção. De que adianta produzir se não há dispêndio, consumo? É o consumo a condição de possibilidade da produção.

\section{Magia e Consumo: uma proposta de aproximação}

Em nossa sociedade extremamente racionalista, apenas no século $\mathrm{XX}$ os aspectos simbólicos ganharam destaque nos estudos sobre nossa sociedade, através de vários pensadores, como Freud, Nietzche, entre outros. Nesta sociedade moderno-contemporânea, o sagrado parece ocupar o espaço do consumo, em suas práticas e representações, que se dão através da narrativa publicitária, fundadora e viabilizadora do consumo. A linguagem publicitária se aproxima da narração mítica, aproximando o fenômeno do consumo do campo do mágico, do simbólico.

De fato, todos topamos acreditar no impossível. Ao olharmos para a vida social que acontece dentro das produções da Comunicação de Massa, um conjunto avassalador de constatações, levando ao inexorável estranhamento, pode ser experimentado. Quando temos notícia de mitos das sociedades tribais onde os animais falam, agem e participam ativamente da vida dos homens, sorrimos, como que traduzindo nossa desconfiança quanto à racionalidade dessas culturas. Penso que, nestes momentos, parece existir um acordo tácito para o esquecimento da semelhança das experiências (ROCHA, 1995, p.31)

E é essa aproximação que inspira a obra de Everardo Rocha em "Magia e Capitalismo" e "A Sociedade do Sonho", que têm como embasamento teórico o pensamento de Lévi Strauss e o seu "Pensamento Selvagem". Em "Magia e Capitalismo", Everardo Rocha é um dos precursores da aproximação entre Antropologia e Indústria Cultural. Lançando mão de uma perspectiva etnográfica, a partir de um grupo de informantes, tenta entender a interpretação de dada narrativa publicitária - de um anúncio de bebidas - através da fala dos mesmos. Em "A Sociedade do Sonho" o campo de análise se dá dentro do anúncio, com o objetivo de entender a sociedade criada nas e pelas narrativas publicitárias. Durante o decorrer do trabalho, entendemos como a sociedade de 
dentro do anúncio alimenta a sociedade de fora, enquanto esta que também concede elementos para essa sociedade midiática, num circuito de retroalimentação do sistema de representações do consumo.

Trago aqui uma análise do termo magia segundo Marcel Mauss, que assim a conceitua: "a magia é, portanto, um fenômeno social.” (MAUSS, 2003, p.174)

Uns confundem a magia com as técnicas e as ciências, outros assimilam-na às religiões. Ela é algo intermediário entre estas e aquelas, não se definindo nem por seus objetivos, nem por seus procedimentos, nem por suas noções. (MAUSS, 2003, p.122)

Pensamos encontrar na origem da magia a forma primeira de representações coletivas que se tornaram depois os fundamentos do entendimento individual (...) uma contribuição ao estudo das representações coletivas. (...) Pensamos ter mostrado, a propósito da magia, de que maneira um fenômeno coletivo pode assumir formas individuais. (MAUSS, 2003, p.177)

Assim, podemos propor algumas aproximações entre magia e consumo, a partir das seguintes afirmações presentes nos estudos de Mauss sobre magia. Ora, o que seria o fenômeno do consumo em nossa sociedade contemporânea se não uma forma de representação coletiva, assim como a magia? E que, assim como ela, também é algo social, coletivo, mas que pode se dar em esfera individual? Até mesmo porque, como nos afirma Durkheim, há uma falsa oposição entre indivíduo e sociedade: há de haver uma criação coletiva para que haja o indivíduo - que é, assim, uma construção social. Dessa forma, o consumo, por exemplo, deve ser considerado como um fenômeno coletivo que tem no indivíduo a sua instância de verificação.

Para entender como um bem considerado profano pode ser sacralizado, é importante entender como se dá a construção do entendimento de sagrado e profano em Durkheim:

Mas o característico do fenômeno religioso é que ele supõe sempre uma divisão bipartida do universo conhecido e conhecível em dois gêneros que compreendem tudo o que existe, mas que se excluem radicalmente. As coisas sagradas são aquelas que a proibições protegem e isolam; as coisas profanas, aquelas a que se aplicam essas proibições e que devem permanecer à distância das primeiras. (DURKHEIM, 1996, p.24)

A aproximação dessa dicotomia de sagrado e profano do fenômeno do consumo se dá pelo entendimento de como se opera a sacralização de um determinado bem ou objeto através de sua representação, gerando um simbolismo atribuído ao mesmo, o que lhe concede uma aura mágica. E qual seria o elemento catalisador dessa representação? A publicidade seria esse mago responsável 
por tirar um simples bem do campo do profano e transferi-lo à esfera do sagrado. Estariam, portanto, assim representados os elementos da magia (MAUSS, 2003, p.55) no fenômeno do consumo:

- Agentes (mágicos ou magos) - para o consumo seria a mídia e seus profissionais

- Atos ou ritos mágicos - seriam as práticas de consumo

- Representações - seriam as mensagens publicitárias e midiáticas

Para conceituação de símbolo ou representação, recorro a Baudrillard e o seu livro Sociedade de Consumo, e ainda a Durkheim. Para este, a representação, a partir de suas análises das crenças totêmicas, seria a manifestação material de uma imagem mental. Com o advento e uso das mídias de massa pela publicidade, para Baudrillard, tudo na Sociedade de Consumo passa a ser representação (simulacro). Por isso, a realidade não significa mais o mundo natural e social função da representação; este seria, agora, forjado pela linguagem que constitui o mundo real. E que linguagem seria essa? Signos e símbolos. Assim, em nossa sociedade contemporânea, para Baudrillard, tudo se transforma em imagem, signo, espetáculo. É a publicidade que elucida e cria essa ambiência. E o que ela busca atingir com isso? Há uma busca pela eficácia simbólica conceito apoiado nas ideias de Edmund Leach - característica das práticas rituais. Mesmo que a mensagem publicitária fale sobre uma possível eficácia instrumental, utilitarista, a magia do consumo só se dará no campo do simbólico.

E aqui, assim como na magia, podemos verificar as condições de possibilidade da relação entre ritual e consumo, pelas questões apresentadas abaixo, baseando-se na obra de Lévi Strauss, que nos traz três condições para haver ritual:

a) O "ator" deve acreditar minimamente na doutrina que ele está "representando", conhecer o seu papel - na sociedade de consumo, esse ator seria a marca anunciante e o publicitário responsável pela mensagem.

b) A sociedade precisa acreditar na eficácia do ritual - seria a própria sociedade de consumo, que não só consome os bens propagados, bem como também a própria publicidade.

c) A pessoa que está sofrendo os efeitos do ritual precisa acreditar na eficácia ritual - na sociedade de consumo, esse elemento é representado pelo consumidor.

\section{Consumo de bens como objetos rituais}


Sabemos que os bens são investidos de valores atribuídos socialmente, mesmo quando se verificam concretizados na esfera do indivíduo. Por isso, como nos afirma Mary Douglas - em seu livro "O mundo dos bens" - "a teoria do consumo tem de ser uma teoria da cultura e uma teoria social." (DOUGLAS, 2006, p.15)

“Os bens (...) são acessórios rituais: o consumo é um processo ritual cuja função primária é dar sentido ao fluxo incompleto de acontecimentos." (DOUGLAS, 2006, p.112)

Os bens seriam marcadores sociais, que comunicam valores acerca do indivíduo ou sociedade que os possui ou consome, dando sentido às constantes trocas rituais de nossa vida social. Através deles, podemos visualizar um mapa de integração social, criando pontes e muros, como nos afirma a autora. Isso porque a depender do conjunto de bens que me cercam estou ligado a um grupo social e desconectado de outro simultaneamente. Os bens afirmam e negam posições e valores sociais através do que comunicam. E, assim como nos rituais primitivos, marcam suas funções e dão sentido a momentos e práticas sociais marcadas na esfera individual. Os objetos carregam histórias, se relacionam entre si e "falam" sobre nós, formando uma gramática. Assim se dá a cultura material, como receptáculo de informação e de significados.

Para que se dê sentido ao contexto cultural de uma dada sociedade, é necessário que haja rituais, a fim de haja um mínimo consenso social, contendo a flutuação de significados através de convenções visíveis. São os bens que concedem e comunicam essas convenções. Afirma-nos Mary Douglas que "viver sem rituais é viver sem significados claros e, possivelmente, sem memória." (DOUGLAS, 2006, p.112). O consumo seria um processo ritual que hoje marcadamente produz uma profusão de significados. E, quanto mais rico em bens é o ritual, mais forte seria a intenção de fixar esses significados. A multiplicidade e complexidade do sistema de bens que hoje nos cerca só reforçam a importância ritual dos mesmos. Por serem parte visível de nossa cultura, tornam inteligível e possível a nossa convivência social através de um mínimo de fixidez de convenções sociais.

\section{Práticas sacrificiais do consumo}

As práticas rituais do consumo podem até mesmo ser sacrificiais - como afirma Daniel Miller em seu livro Teoria das Compras. Afirmam-nos Mauss e Hubert em sua obra sobre sacrifício que este sempre implica uma consagração: em todos eles, um objeto passa do domínio comum, ao domínio religioso - é consagrado. “(...) o sacrifício é um ato religioso, que mediante a consagração 
de uma vítima modifica o estado da pessoa moral que o efetua ou de certos objetos pelos quais se interessa". (MAUSS; HUBERT, 2005, p.19)

Com base nesse conceito e outros atribuídos por outros autores acerca do sacrifício, Daniel Miller constrói em "Teoria das Compras" uma relação entre compras de víveres para o lar como um ato sacrificial. Essa construção se dá a partir de sua observação de como esse abastecimento acontece em casas da Inglaterra, acompanhando donas de casa, num trabalho etnográfico, para que a partir daí possa propor uma teoria. Miller constata que:

Tanto nos rituais de sacrifício como nas compras, as representações de excesso e dissipação são sistematicamente negadas através da transformação de ambos em situações de transcendência. No caso do sacrifico, ela se materializa em uma separação entre aquilo que é ofertado à divindade e aquilo que é utilizado para consumo humano. No caso das compras, a imagem de transcendência é obtida pela transformação do gasto e da dissipação em uma atividade de economia e parcimônia. (MILLER, 2002, p. 15)

Em nossa sociedade contemporânea, o sacrifício estaria ligado ao consumo como momento em que há o dispêndio do que foi produzido, assim como nas sociedades primitivas quando o mesmo ocorre ao final da produção da lavoura ou criação de animais.

$\mathrm{O}$ ato de comprar, assim como o sacrifício, constrói o divino da maneira com um determinado sujeito deseja. A fumaça que sobe à divindade durante a confecção do alimento no lar representa a concretização do desejo desse sujeito. E o propósito de assim se comportar não seria tanto para atender simplesmente o desejo desse outro, mas sim de continuar se relacionando com ele através desse ato sacrifícial.

\section{A ética romântica e o espírito do consumismo moderno}

Depois da associação empregada por Weber entre protestantismo e capitalismo, Calin Campbell nos propõe que também o romantismo seria crucial para entender o sistema cultural do consumo como conhecemos e vivemos hoje em nossa sociedade contemporânea. Para o autor, o consumo seria um "fenômeno moderno que, na verdade, liga diretamente as duas coisas": o econômico e o romântico. (CAMPBELL, 2001, p. 9)

Para Campbell, seriam características do consumidor moderno o hedonismo, o binômio sentimento-intuição, em contra-ponto ao binômio autoridade-razão, o que concede a este uma ânsia insaciável pela novidade.

Os produtos midiatizados carregariam um potencial material de sonho, segundo Colin Campbell. Para ele não seria a comunicação de massa a responsável por incutir essa prática do 
devaneio, sendo esta, para ele, uma característica da sociedade moderna, que torna o sonho um hábito a partir da ética romântica. A publicidade de fato alimenta, mas não cria o devaneio, o sonho, a imaginação. A esse hábito de sonhar acordado, pensando sempre na próxima experiência de consumo que nos dará prazer, Campbell dá o nome de day dream.

\section{Considerações finais}

Num mundo que tem pressa, talvez apenas a eficácia da mágica consiga atender aos desejos efềmeros, inesgotáveis, que almejam resultados imediatos, sem esforço ou longo tempo investido. Uma sociedade que vive o tempo presente parece encontrar na mágica do consumo a solução para as suas questões mais profundas, como ser feliz, belo e bem sucedido.

Segundo Everardo Rocha, em apresentação ao livro de Mary Douglas, o "consumo é sistema de significação, e a verdadeira necessidade que supre é a necessidade simbólica." (DOUGLAS, 2006, p.16). Se assim se dá em nossa sociedade contemporânea, a dita sociedade de consumo, podemos afirmar a extrema pertinência e relevância do estudo dos aspectos mágicos, rituais e simbólicos em nossos tempos, que se viabilizam através das práticas e representações do consumo.

Reflexões recentes sobre o fenômeno do consumo trazidas, por exemplo, por Canclini, visam "entender como as mudanças na maneira de consumir alteraram as possibilidades de cidadania" (CANCLINI, 2008, p.29). Em tempos de aquecimento global e convenções mundiais sobre clima e futuro do planeta, o tom moralista em torno do consumo ganha força e propõe que apenas o consumo consciente faz de você um cidadão decente.

Muito ainda temos para discutir acerca desse fenômeno social, que vem tendo sua narrativa - a publicidade - fortemente regulamentada por lei, com proibições e restrições, por exemplo, a mensagens publicitárias de cigarro, bebidas alcoólicas, alimentos infantis e medicamentos, dentre outros segmentos. Tais práticas implicam no entendimento de uma recepção passiva e permeável a qualquer sugestão publicitária como se esta fosse uma ordem. Faz-se necessário não subestimar tanto a nossa capacidade de reflexão como receptores dessas mensagens.

Assim, não é nesta rápida e rasteira revisão bibliográfica que, de longe, encerram-se as análises do vasto tema consumo, com todo um campo de estudo a ser consolidado, por ter sido durante algum tempo - até os dias atuais - assunto tabu nas Ciências Sociais. Aos autores desbravadores do tema, o meu muito obrigada por terem coragem de abrir o campo no qual agora sou mera iniciante, tateando os primeiros passos na trilha desse conhecimento. 


\section{Referências}

BAUDRILLARD, Jean. A socie dade de consumo. Lisboa: Edições 70, 2008.

CAMPBELL, Colin. A ética romântica e o espírito do consumis mo moderno. Rio de Janeiro: Rocco, 2001.

CANCLINI, Néstor García. Consumidores e Cidadãos: conflitos multiculturais da globalização. Rio de Janeiro: Editora UFRJ, 2008.

DOUGLAS, Mary; ISHERWOOD, Baron. O mundo dos bens. Rio de Janeiro: Ed. UFRJ, 2006.

DUMONT, Louis. O individualismo: uma perspectiva antropológica. Rio de Janeiro: Rocco, 1985.

DURKHEIM, Émile. As formas elementares da vida religiosa. São Paulo: Martins Fontes, 1996.

MAUSS, Marcel. Sociologia e Antropologia. São Paulo, Cosac Naify, 2003.

MILLER, Daniel. Teoria das compras. São Paulo: Nobel, 2002.

ROCHA, Everardo. Magia e Capitalismo. São Paulo: Brasiliense, 1995.

A sociedade do sonho. Rio de Janeiro: Mauad, 1995.

VEBLEN, Thornstein. A teoria da classe ociosa. São Paulo: Abril Cultural, 1980. 